Chronotopes and timespace contexts: Academic identity work revealed in narrative fiction

\author{
David Pick* \\ School of Management, Curtin University, Perth, Australia \\ Curtin University \\ GPO Box U1987 \\ Perth 6845 \\ Western Australia \\ Email: d.pick@curtin.edu.au \\ Ph: +61 892662705
}

Christine Symons

Curtin Business School, Curtin University, Perth, Australia

Curtin University

GPO Box U1987

Perth 6845

Western Australia

Email: c.symons@curtin.edu.au

Ph: +61 892662429 
Stephen T.T. Teo

New Zealand Work Research Institute, AUT Business School, AUT University, Auckland, New

Zealand

AUT University

Private Bag 92006

Auckland 1142

New Zealand

Email: stephen.teo@aut.ac.nz

Ph: +64 99215433

* Corresponding author 


\section{Chronotopes and timespace contexts: Academic identity work revealed in}

\section{narrative fiction}

In this paper, academic identity work is explored through an examination of its portrayal in a work of narrative fiction using a conceptual tool from literary studies. We found that such an approach provides insights that would otherwise be difficult to uncover by more conventional methods. The analysis reveals academic identity work as an ongoing narrative process of interplay between internal (individual) perspectives, actions, and stories and external (organisational and institutional) influences. It is also found that timespace contexts - chronotopes - play an important role. We show that maintaining a coherent academic identity is fraught with challenges, particularly when navigating the multitude of perspectives on what it means to become an academic.

Keywords: academic identity, chronotopes, identity work, narrative fiction, novels, timespace

\section{Academic identities under pressure}

Being an academic can be like working in a hall of mirrors. As they reflect on their work and who they are, academics find many different images looking back at them. It seems that there are multiple, expanding and conflicting ideas about what it is to be an academic (GuzmánValenzuela and Barnett 2013) to the extent that in the contemporary university, academics do not or indeed cannot know, who they are (Barnett 2000). Something is compromising their ability to establish a stable and coherent sense of identity.

The research about academic identities suggests that ongoing changes happening in higher 
education institutions around the world are putting significant pressure on how academics see themselves. Evidence for this trend is provided in a variety of studies in Europe (e.g.

Whitchurch 2012; Ylijoki and Ursin 2013), North America (e.g. Rhoades 2007), South Africa (e.g. Liebowitz, Ndelbele and Winberg 2013), South America (e.g. Guzmán-Valenzuela and Barnett 2013), Australia (e.g. Churchman and King 2009), and New Zealand (e.g. Billot 2010). This continuously changing environment is characterised by the globalisation of higher education and the rise of 'supercomplex' universities where there are a multitude of frames of understanding, action, and self-identity that are all contestable (Barnett 2000). To fit the surroundings of this 'runaway world' (Giddens 2002), universities are becoming 'liquid organisations' that have no durable structures, particularly those that relate to facilitating long-term job prospects with a single organisation and thus a 'career' (Baumann 2000). Delanty $(2008,127)$ observes that as universities have become 'liquid', academics have been placed 'in a constant state of being repositioned'. As a consequence, there are rising tensions between the managers of higher education organisations that want academics to conform to an identity constructed within the broad pre-defined boundaries of neo-liberal/managerial discourses (Harris 2005; Henkel 2005) and the way individual academics define themselves (Winter and O'Donohue 2012; Ylijoki and Ursin 2013). Out of these tensions there arises two opposing forces. One is fragmentation that refers to the splitting an individual academic's identity into an increasing number of variegated, simultaneous, and shifting notions of the self (Alvesson, Ashcraft and Thomas 2008). The other is coherence that refers to maintaining a sense of unique self-expression and wholeness across a set of identities over time (Ashforth, Harrison and Corley 2008). In referring to these forces, Churchman and King (2009) observe that it is now only the inner academic identity that provides any sense of coherence that is itself often under pressure. This situation has resulted in academic identities being under threat (Clegg 2008), becoming increasingly fragile (Knights and Clarke 2014), 
unstable (Guzmán-Valenzuela and Barnett 2013), and fluid (Leibowitz, Ndebele and Winberg 2013).

Given the supercomplex environment in which academic identities are currently being forged, we argue that a broader and more multifaceted analysis is needed. In light of the discovery that supercomplex organisations contain nested and crosscutting identities and that individuals tend to identify with multiple loci (Ashforth, Spencer and Gorley 2008), we conceptualise academic identity as being multifaceted (Billot 2010) and dynamic (Henkel 2005) and consequently best analysed as a process (Schultz, Maguire, Langley and Tsoukas 2012) termed academic identity work. Many researchers provide insights into identity work at the organisational (external) level (Alvesson and Willmott 2002; Ashforth et al. 2008) while others have shown how at the individual (internal) level, interactions with colleagues can shape the identity work process (Empson 2013). While there has been extensive research into identity work, there remain a number of unaddressed theoretical and methodological issues. In particular, the commendable empirical attention given to academic identities over the past two decades has yet to be fully developed into integrated theory that will enhance understanding of the identity work process (Ashforth et al. 2008). One of the major challenges is to find ways of conceptualising and analysing academic identity work as being complex, rich, holistic, and situated in nature. To begin addressing this challenge, we define identity work as an ongoing process and flow of construction, reconstruction, and performance (Gioia and Patvardhan 2012). At its core is narrative that is a 'social, purposeful process, intended to produce meaning in a situation' (Lorino and Tricard 2012 204). The aim of this article is to investigate identity work as a narrative process and in doing so provide new theoretical and methodological insights. To this end, we draw on literary theory and apply this to examine the portrayal of academic identity work in a novel that captures it as a 
dynamic and complex process.

Literary theory has been a focus of much organisational research and found to be a powerful means of generating new theoretical and practical perspectives (De Cock and Land 2005). In this study we employ one concept from literary theory - the chronotope. The chronotope helps to understand how time and space is portrayed in novels (Bakhtin 1981). In the context of this research, the choronotope helps to capture how identity work is a contextually situated construction and sharing of meanings and interpretations of what it means to be an academic. An everyday example of a chronotopic phenomenon is the teaching timetable. It organises the activities of academics through time and space. At the organisational level, it tells them where they are to be and for how long at particular times of day, at particular times of year. At the individual level, the classroom where academics are directed to be by the timetable is itself chronotopic. The classroom space varies, and how time flows and what takes place within this space is a dynamic of influences between lecturer, students, and the environment. When applied to the analysis of fictional narratives, the chronotope makes it possible to achieve in-depth insights and understandings about the factors affecting identity work. For example, JM Coetzee's novels about post-apartheid South Africa involve a sophisticated examination of the influence of time and place on identities (Barnard 2006). In employing chronotopes in our analysis we contribute to the literature in three main ways. Firstly, we provide new conceptual and methodological perspectives on researching academic identity work through the application of literary theory, secondly we demonstrate the usefulness of narrative fiction as a source of data for researching academic identity work, and thirdly, we illuminate and explore some of its previously hidden dimensions (Ashforth et al. 2005). 


\section{Research into academic identity}

The literature about academic identities is broad and constitutes an important theme in higher education research that has developed in three waves. The first wave of research identifies academic identity work as an important phenomenon and describes influencing forces. Nixon (1996) was one of the first researchers to suggest that there is a crisis of academic identity. In subsequent years, Henkel (2000; 2005) and Barnett (2000) published seminal works. Insights from these authors led to a growth of interest in researching academic identity. The most influential idea to emerge from this wave is the discovery that academic identity is fragmenting as a result of emerging conflicts of values, multiple functions, and loosening of institutional boundaries in higher education.

In the second wave, the ideas outlined by Barnett and Henkel are developed further. The second wave is best introduced with reference to the edited work by Barnett and Di Napoli (2008). This book added greatly to our understanding of academic identity by drawing attention to it as a social construction. This arises from a process of interaction between agency (voice) and structure (organisations) in which there is an increasing prevalence of identity 'breakdown'. These themes can be seen in the work of Harris (2005) and Clegg (2008) in which arguments are advanced about how changes in higher education are threatening academic identity. Harris (2005) builds on the idea that academic identities are fragmenting, arguing that this trend is connected to the contextual effects of neo-liberal higher education reform on institutional (structure - organisational) and individual (agency voice) factors. This apparent triumphing of structure over agency led some to argue that academics are becoming 'managed professionals' subject to a range of external managerial controls over their work and as a consequence limiting the identities available to them (Rhoades 2007). The changes described above come together in Clegg's (2008) work in 
which she describes an emerging crisis in academic identities, contending that threats arise from academics being forced into responding to a rapidly changing higher education environment within organisationally prescribed limits. Clegg (2008) concludes that they do this by shaping and reshaping their identities to the extent that they become 'hybrids' of internal (or private) profession-based identity combined with external (or public) identity that are aligned with new university structures. In light of this research, the idea of tensions arising between external forces that create fragmentation of identity and the desire of academics to have a coherent internal sense of self emerges. Churchman and King (2009) use the term 'hybridity' to describe how academics develop internal (private) identities that are kept 'in the shadows' while at the same time maintaining an identity that conforms to 'monolithic organisational stories'. The idea of hybridity is given greater form by Whitchurch $(2008 ; 2009)$ who describes the changes occurring in higher education as blurring the boundaries between administrative (professional) roles and academic roles that are challenging our current understandings about academic identity, particularly the emergence of new 'blended identities' that do not conform to the traditional distinction between 'professional staff' and 'academic staff'.

This interaction of internal and external forces in the academic identity work process is examined by Archer (2008). She identifies a conflict between the dominant performative, managerialist (external) and the personal (internal) constructions of authenticity and success arising from the constantly shifting performance expectations of universities coming up against the more stable personal beliefs and values about being an academic. This tension between external and internal influences renders academic identity insecure and unstable. The analysis by Archer (2008) raises concern about other tensions arising in identity work that are the focus of attention by researchers in this second wave. These tensions stem from 
an incongruence of values between those pertaining to the inner professional self and the outer organisational self (Winter 2009), constant revision of identities due to tensions between multiple and context-specific identities (Billot 2010), as well as insecurities resulting from the fluctuating nature of identity work as individual and collective influences ebb and flow (Smith 2010).

The edited book by Gordon and Whitchurch (2010) marks an important milestone in the development of research into academic identities, beginning a third wave of research. This wave builds on previous research about the tensions between the individual and the organisation, identifying such tensions as an important factor in academic identity work. While second wave research draws attention to examining the interplay between internal and external factors, third wave research focuses more on individuals and how they can build more robust responses to higher education reform. This often includes a normative perspective marked by the emergence of reflexive studies. Normativity is evident in research that examines fragilities and insecurities in an environment where there are unrealistic institutional expectations (e.g. Knights and Clarke 2014). The focus on individual responses is evident in work that highlights 'identity struggles' between personal commitments to teaching and organisational demands (Skelton 2012) and how academics can resist the potentially corrosive effects of performative and managerialist cultures on identities (Clarke, Knights and Jarvis 2012). In these struggles, Smith (2012) argues that hybrid identities provide cover for academics to pursue the work they aspire to do while at the same time conforming to the demands of funding bodies and their university. In doing so, they continually reposition themselves to ensure their research remains relevant. As a result, academic identities have become more complex and continually shift in response to changing institutional demands (Smith 2012). Whitchurch (2012) examines this complexity in relation 
to the expansion of academic identities into new 'project oriented' domains that lie outside the mainstream. This theme is developed by Fanghanel (2012) who identifies the emergence of multiple voices and plurality of values within academic identities as they become a 'complex mix of endorsement and rejection of performativity' in a 'constant project of identity construction and reconstruction' (Fanghanel 2012, 29). This is reflected in the findings of Liebowitz, et al. (2013) who argue that this process is fluid and changeable in which academics position and reposition themselves within their professional and institutional contexts.

Third wave literature also draws attention to how the changing realities faced by academics are creating tensions between emerging multiple identities. Such tensions are examined by Ylijoki and Ursin (2013) who identify a polarisation of academic identities resulting from varying effects of higher education reform ranging from 'resistance' to change, to 'success' in adapting to change, through to the 'neutral, by-stander' position where the focus is on maintaining work-life balance. It is argued that tensions like these can negatively affect motivation, self-efficacy, commitment, job satisfaction, and effectiveness (Winter and O'Donohue 2012). The evidence though is mixed. Alexiadou and van de Bunt-Kokhuis (2013) examine the development of 'transnational identity' in response to change, providing the example of academics who successfully work and move between institutions internationally.

In general terms, third wave research suggests that the multiple identities available to academics seem to have created a situation where identity is a continuous work in progress, characterised by an ongoing combining and recombining of diverse professional and personal selves, in which the personal self is the most important (e.g. Sheridan 2013). This individual 
perspective on academic identity work has led to an emergence of reflexive studies, in particular the application of auto-ethnography to provide personalised accounts. As Learmonth and Humphreys (2012) argue, auto-ethnography exposes to critical scrutiny the institutionally approved discourses of academic identity work and how these connect to the intimate stories of the academic self. This approach is adopted by Winkler (2013) to draw attention to the micro-processes of identity work that help maintain a coherent sense of self within a changing institutional environment, while Empson (2013) examines how the tensions created by conflicting identities may be reconciled. For King (2013) academic identity work is a personal project focused on reconciling individual (internal) and broader (external) contextual factors of (global) higher education. Fitzmaurice (2103) supports this idea concluding that academic identity work is an ongoing process involving the individual and various academic roles they play which in turn are influenced by institutions, peers, and individual values and beliefs.

As change continues in higher education, the hall of mirrors grows ever longer. The three waves of literature have significantly developed our understanding of academic identity work, but as more and more facets are revealed there remain a number of unresolved theoretical and methodological challenges. These require research attention in order for our understanding of academic identity work to develop further.

\section{Theoretical and methodological challenges}

When compared to the organisation and management literature, higher education research into academic identity work remains relatively under-theorised. To address this gap we examine the extent to which people interpret, modify, embrace or reject elements that make up academic identity (Watson 2008). We attempt to develop a conceptual model that captures 
the fluid, situated nature of identity work that is based on specific instances of identity construction or modification (Koerner 2014). This includes full consideration of place and time as they saturate all areas of social life (Brown and Humphreys 2006), including those inhabited by academics (Alexiadou and van de Bunt-Kokhuis 2013).

Methodological challenges are also evident when researching academic identity work. One problem is that data may not always produce realistic accounts or not accurately reflect the process. This is because of the difficulties collecting the required intimate personal details through interview or gaining access for participant observation in which negative dimensions of identity work might arise. As a result, the focus of research has tended to be on some of the more easily identifiable aspects of identity work (see the discussions by Learmonth and Humphreys 2012 and Lerum 2001). To address this problem, some researchers have conducted auto-ethnographic studies in an attempt to engage in new forms of study into identity work that is both evocative and analytical. However, this approach could result in researchers becoming too familiar with the narratives of identity work being studied, generating a tendency to be somewhat uncritical of the data being analysed (Learmonth and Humphreys 2012).

\section{Narrative and its place in identity work}

In response to these challenges, researchers in many disciplines have turned to narratives as a source of data for examining identity work (Alvesson et al. 2008). This is because examining narratives is a useful way of understanding how identity is expressed and constituted; telling a good story helps people create meaning and helps make an identity more credible (Ibarra and Barbulescu 2010). Identity work then, like other organisational processes, is inherently 'narrative' (Boje 2001; Lorino and Tricard 2012). Novels are also narratives in that they 
convey a story and thus can be regarded as appropriate empirical material for research (Rhodes and Brown 2005). They provide a particularly rich source of data (Boland 1994) in which attention is drawn to the depiction of how individuals experiment with and negotiate different possible identities (Alvesson et al. 2008). In spite of these strengths, novels have yet to receive a great deal of attention by identity researchers.

\section{Narrative fiction and research into academic identity work}

Due to the interpretive and subjective nature of narrative fiction, the findings gleaned from such texts are necessarily equivocal. Nonetheless, we contend that they are valid for two main reasons. The first is that there are close connections between identity work and novels. Just as identity work is a narrative in the form of a social performance of the self 'situated and accomplished with audience in mind' (Reissman 2008, 106), novels too are performances of narratives that are for, and interpreted by, an audience. Secondly, we argue that organisational life is a regular subject of novels (Patient et al. 2005) to the extent that organisation can be found at the heart of the literary and vice versa (De Cock and Land 2006). This arises from an ontological fit between fictional narratives and organisational life. As narrative constructions they are both human creations and, consequently, are uncertain and ontologically insecure (De Cock and Land 2006). This means that fictional narratives and descriptions of organisational life produced by researchers are often incomplete and open to multiple interpretations. This ontological fit also has epistemological implications because organisations and any accounts of them (fictional or empirical) are contestable and thus no single, authoritative representation is possible (Rhodes and Brown 2005). Because of this, an interpretive epistemological position is most appropriate, grounded in the interaction between the researcher and the text (Patient et al. 2005). 
When using novels as a source of data, how to examine the narratives requires serious consideration. Three alternatives are possible: a thematic analysis (description of the narrative), a structural analysis (organisation of the narrative), or a dialogical/performance analysis (characters, their motives, timing and locations of the narrative) (Reissman 2008). Since we are taking the view that identity work is a form of performance, it is appropriate that we adopt the third approach. As such we are not only examining narrative processes but also interrogating its ambiguities. In doing this, we create 'more complex and nuanced account[s] of self and identity' (Learmonth and Humphreys 2012, 3).

There is a long and rich history of novels about higher education (Johnson 1995; Tierney 2002). These novels are broadly categorised into 'campus novels', for example, The Marriage Plot (Eugenides 2011) that focus on students, and 'academic novels', such as On Beauty (Smith 2005) that feature those who work as academics (Williams 2012). Given the prevalence of novels about higher education and the growing recognition of novels as sources of inspiration and data for research, it is somewhat surprising that there are few studies in the literature that draw on this source. Notable exceptions are Tierney $(2002 ; 2004)$, Johnson (1995), Williams (2012), and Thelin and Townsend (1988). Of these, only Tierney (2012) studies aspects of academic identities in academic novels. Learmonth and Humphreys (2012) study academic identities, but do not use an academic or campus novel as a data source. Instead, they examine Robert Louis Stephenson's gothic mystery, The Strange Case of Dr Jekyll and Mr Hyde.

The main benefit of using academic novels is that they provide a means of tapping into the inner desires and external constraints of academics' lives that are difficult to access by other means (Johnson 1995). Contemporary academic novels illuminate 'anxiety narratives' 
that arise from the far-reaching change happening in higher education (Williams 2012). Thus, even though the worlds described in academic novels are imaginary - though realistic - they convey truths and challenge conventional thinking in ways that would otherwise go unexpressed. In particular novelists can 'by harnessing the power of imagination and identification ... enable us to appreciate and explore in greater depth the drama ... that is present yet generally unnoticed in the most mundane of encounters' (Knights and Willmott 1999, 8). The importance of using imagination in research lies in that it provides an alternative to incremental, consensus-based research, encouraging consensus-challenging work that problematises commonly held assumptions leading to new and interesting theoretical insights (Alvesson and Sandberg 2011).

\section{Understanding academic identity work as being chronotopic}

In our endeavour to conceptualise academic work as a narrative process and use novels as a source of data, it is useful to apply analytical tools from literary theory to achieve a better understanding. In particular, it is important to capture the role of space and time, and how it assists in the search for a theoretical base. Earlier in this paper, we introduced the idea of the chronotope and gave an example of the teaching timetable. In literary analysis, Bakhtin (1981, 84) first defined the chronotope as an expression of 'the inseparability of space and time ... that defines genre and generic distinctions' of a novel. In developing this definition, Bakhtin (1981) identifies twelve generic literary chronotopes dating back to Ancient Greek mythology (e.g. Greek Romance), through to more recent literature (e.g. The Road and The Castle), but points out that major chronotopes beyond those he describes can be identified and in addition, there are an unlimited number of minor chronotopes.

Boje $(2001 ; 2008)$ applies chronotopes to help conceptualise the 'storytelling 
organisation' in which narratives are of central importance. When applied to the study of identity work in organisations, the ways in which chronotopes represent the integration of time and space help us to understand how it is contextual; it helps encapsulate how individuals read the social and institutional environment and helps explain how academic identity is defined and accepted by society (Lorino and Tricard 2012). For example, chronotopes help capture how identity work involves the contextually situated construction and sharing of meanings and interpretations of what it means to be an academic. In this setting, chronotopes are also referred to as 'timespace' (Raggatt 2014).

In literary analysis, chronotopes provide the internal, organising structure of a narrative and define the relationship between a narrative and reality (Bakhtin 1981). Identity work is fundamentally a narrative process and as such chronotopes provide a means of examining the ways in which identities are established, developed and structured, and how they are connected to their organisational and institutional realities (Lorino and Tricard 2005). Academic identity work can thus be captured as a product of chronotopic influences on the two-way relationship between externally available academic identities and internally defined self-identities. Identity work necessarily occurs in particular locations over time that together establish particular timespace (chronotopic) contexts that influence the construction of academic identities at the organisational and institutional levels and the varying ways that individuals construct, modify, maintain, and perform their identity as an academic (Figure 1).

Insert Figure 1 about here 
In the next section we develop this perspective by analysing a work of literary fiction. In doing so we identify and examine four major chronotopes of academic identity work that together provide insights into internal and external influences on the process and their timespace contexts.

\section{Methodology}

In our analysis, identity work is conceptualised as being a narrative process that is driven internally by individuals with (and sometimes against) the external limits set by organisations. For this analysis we chose On Beauty by Zadie Smith. This novel was selected for several reasons. Firstly, as it is written in the 'realist' style, it portrays the search for identity in ways that are close to the everyday realities of people's lives (Smith 2006). The novel lays bare issues and experiences that are widespread and significant to academic identity work in contemporary universities, offering clear and intimate descriptions that lend themselves to detailed analysis. The novel also provides representations of a character's most intimate thoughts and deeds as well as those influences they remain unaware of. These are often factors that other forms of data collection would be unlikely to access (e.g. extra-marital affairs, unethical conduct, strong emotions, etc.). The multi-voiced nature of the narrative allows us to see the story through various lenses enabling us to reflect not only on the personal musings of individuals on their own identity but also how others see them. On Beauty is composed of multiple narratives, voiced in different ways within different chronotopes, rather than having a single narrative organised around one chronotope. As such, the novel allows us to illuminate as yet unexplored and difficult to examine dimensions of academic identity work.

In conducting this research we are conscious that we are drawing on a single data 
source (i.e. the novel On Beauty). In this study we apply Reissman's (2008) criteria for assessing narratives: trustworthiness, persuasiveness, coherence, and pragmatic usefulness. As a source of data the novel is trustworthy as it is written in the 'realist' literary style (Smith 2006) and as such is an accurate reflection of social realities. As Menard-Warwick (2011) contends, in realist fiction, the novelist creates an entire social world inhabited by characters with relevant and realistic identities. In terms of persuasiveness, the events in On Beauty are presented in ways that resonates with readers (Patient et al. 2005) and while it is 'fiction' it contains truths as it provides real insights into social situations (Philips and Zyglidopoulos 1999). The narrative of On Beauty is a coherent, contemporary account of an academic struggling with their identity and as such has pragmatic usefulness as it provides insights into academic life and passions and thus opportunities for research that extends our understanding of academic identity work.

In sum, On Beauty provides a rich source of data, providing realistic and intimate accounts of identity work that are difficult to access through more conventional research methods (Learmonth and Humphreys 2012; Lerum 2001) and as such it has revelatory value (Yin 2009). As a single case it also has critical value in that this study contributes to knowledge and theory building about academic identity work and as will be shown, helps refocus future investigations (Yin 2009). One particular advantage of this approach is that the entire data source (the novel) is available for anyone to read and test our interpretations and findings (Patient et al. 2005).

\section{Data}

We focus on one of the main characters in the novel, Howard Belsey, following his experiences of identity work. We undertook the analysis of the text through three close readings. The first reading familiarised us with the story. Discussions were then held about 
characters, plot, etc. to ensure that there were common understandings. On the second reading each researcher made notes (using an iPad e-reader) and highlighted the specific passages in the novel that connected to identity work. This selection of passages was shared between the researchers who coded and categorised them, identifying broad concepts and themes that capture the significance of identity work and its contextual descriptions. We undertook a third reading of the novel to ensure the analysis as presented was comprehensive. The results of the analysis were then compared to other published work about academic identity. This study relies on a number of short excerpts from the novel to present exemplary illustrations of the identity work process (Patient et al. 2005).

\section{The Novel}

\section{Context}

Howard Belsey is a left-leaning academic, from an English working-class background, who at the age of 57 remains untenured at Wellington University where he has been working for the last 10 years. Wellington University is a fictional, small liberal arts university located in the town of Wellington near Boston, Massachusetts. Most of the events in On Beauty take place in two locations: London and Wellington. Much of the action in Wellington takes place in family homes, in and around the Wellington streets, and on the university campus. In London, the narrative helps to explore Howard's past, in particular his formative years.

The backstory to the novel is important. One relevant element of this is the death of Howard's mother when he was 11 years old. Howard and his father were never able to reconcile their grief. Another occurs when Howard made an error in a critique of another scholar's (Sir Monty Kipps) work. As a result, Howard experienced public humiliation within academic circles and there ensues an intense conflict of values in the course of the 
novel. Sir Monty is English of Jamaican origin whose academic, cultural, and political values (right, neo-conservative, reactionary) are opposed to those held by Howard (left, liberal, postmodern). Both Howard and Sir Monty are scholars specialising in the work of Rembrandt. Sir Monty has published a popular academic book on the subject, while Howard's endeavours to write a similar text remain unfinished. Howard's identity challenges become acute with the arrival of Sir Monty Kipps at Wellington University.

\section{Chronotopes - When, where and how academic identity work takes place}

In the following sub-sections we examine academic identity work through a series of chronotopes that influence identity work at various levels (as seen in Figure 1). The first subsection describes the childhood chronotope that influences identity work through external (institutional) and internal (individual) forces - such as class, race and gender. The second focuses on the chronotope of career struggle. Here we see how varying professional cultures affect identity work as academics struggle to maintain coherence and meaning to their identity in the face of polarising influences (Ylijoki and Ursin 2012). These themes are picked up and developed in the third sub-section that focuses on changing realities. In this section, a variety of forces that shape identity work are evident including those that lead to ambivalence about change (Fanghanel 2012) and pressure arising from the need to 'perform' (Clarke Knights and Jarvis 2012). This is where identity work becomes a complex mix of internal (individual) and external (organisational and institutional) influences (Clegg 2008) that are difficult to reconcile (Sheridan 2013). The last sub-section examines the chronotope of setting the future, where the past, present and future collide. In this final part of the analysis we illuminate how individual academic identity work, organisational narratives, and institutional narratives combine to create an on-going process of identity work in which we consider who we were, who we are, and who we want to become that occur against a 
constantly shifting background of institutional, professional and personal circumstances (Fitzmaurice 2013) (Table 1).

Insert Table 1 about here

\section{Childhood chronotope}

In the following two passages from the novel, Howard Belsey muses on his childhood memories and how these have affected the way he sees the world and his place in it. The tensions between external and internal influences are illustrated; in particular the influence of social class, race, and culture and how Howard strives to create a new identity for himself to the point of alienation, separation, and shame about his social roots.

And so on the first landing we have a large representation of one of the English Belseys, a charcoal portrait of Howard's own father, Harold, hanging high up the wall as is decent, wearing his flat cap ... Howard himself hates it, as he hates all representational painting - and his father. (page 18)

... he felt like he'd been sitting here with Harry these forty years, both of them still tied up in the terrible incommunicable grief of Joan's death. For they fell into the same patterns at once, as if Howard had never gone to university (against Harry's advice), never left this piss-poor country, never married outside his colour and nation. He'd never gone anywhere or done anything. He was still a butcher's son and it was still the two of them, still making do ... Two Englishmen stranded together with nothing in common except a dead woman they both loved. (page 294) 
These excerpts provide a clear depiction of how the childhood chronotope influences identity work. To begin there is sameness (making do), then difference (nothing in common) and transition as Howard, escapes his childhood social milieu (he went to university) and tries (unsuccessfully) to come to terms with the traumatic event of his mother's death (tied up in grief). The childhood chronotope re-emerges at later times and locations (at university and the present day) in the novel as tensions arise between his current identity as a university academic in the USA, his mixed-race family, and his childhood background.

\section{Career struggle}

The career struggle chronotope in the novel illustrates the timespace where interactions between internal and external influences affect Howard's identity work. External (organisational, professional, and institutional) forces appear against a backdrop of increasing polarisation of values within the university and in the shape of gender and family. In the first instance Howard comes into conflict with Sir Monty Kipps. In one incident, Howard tries (unsuccessfully) to force the content of Sir Monty's lectures to be considered by the faculty academics before they are given on grounds that they contravene the 'internal hate laws' of the university. In another, motivated by a (mistaken) belief that a book about Rembrandt by his rival (Sir Monty) contains incorrect detail. Howard makes an error in a published critique that is smugly and publicly pointed out by Sir Monty. In the personal sphere, events take place in the family home where Howard's extra-marital affair is discovered. Rather than telling the truth and risking his current identity as a family person and respected academic, out of shame, Howard decides to lie. Both these events lead to professional and personal humiliation and his identity as a respected academic being challenged.

\footnotetext{
'All in favour ... of the lectures going ahead without prior consultation.'... With the small
} 
exception of Howard's small pockets of support, all hands went up. (page 131)

In his letter he directs his attack at the 'Self-Portrait' of 1629 that hangs in Munich.

Unfortunately for him, I make it more than clear in my article that the painting under discussion is the 'Self-Portrait with Lace Collar' of the same year, which hangs in The Hague. (page 28)

In front of the entire academic community Howard had picked up some rope and hanged himself. (page 29)

But Howard had been discovered and confronted in the oldest way - a condom in the pocket of his suit ... He had many choices in front of him that day, but the truth had simply not been one of them, not if he wanted to retain any semblance of the life he loved. (page 109)

These passages illustrate that academic identity work depends not just on 'academic work' at the individual and organisational (internal/external) levels but also at the (external) institutional level because it connects to one's domestic and private life. As shown in Table 1, the tensions this creates become apparent particularly when one encounters difficulties in the private sphere. In the professional arena, there is the dimension of not conforming to expected social and professional norms and standards. This leads to humiliation and embarrassment of losing a moral argument (the lectures went ahead) and being an expert who makes a significant error (Howard ... hanged himself). In the private domain Howard's struggles are apparent arising from the dimensions of desire in the conducting of an affair and the shame associated with discovery (in the oldest way).

\section{Changing realities chronotope}

In this sub-section, we turn to changing realities. The characteristics of this chronotope are 
varied and, in a similar way, are the influences affecting Howard's academic identity work. Like the career struggle, the changing realities chronotope refers to the university campus and in the home. This chronotope differs in that the encounters that characterise changing realities convey academic identity work as a process of trying to maintain an identity in the face of shifting organisational, institutional and personal realities. In the novel, Smith likens the way Howard goes about identity work to a theatrical performance. It is clear though that it is more than this. As shown in Table 1, it is also about being connected to the realities of family life and engaging with changing organisational values and expectations that Howard seems unable to do. There is a shift of cultures among the senior academics as they adopt managerialist discursive practices that are reflected in their decisions.

What are you talking about Jack [The Faculty Dean]? You're talking to me like a management manual? (page 158)

The pressures from work and home also become too much and Howard's identity begins to fracture. On campus, one significant part of the changing realities is the appointment of Sir Monty Kipps to the university and as time passes, Howard comes to realise that his identity struggles and resistance to change in his professional and personal spheres are failing. At the university, he is unable to adapt to the changing technologies used in the course of academic work. One poignant example is that Howard continues to insist on using an overhead projector rather than Powerpoint when teaching because,

He was beyond the point of learning new tricks. (page 142)

[He] looked dejectedly at the [computer] hardware before him. (page 382) 
Howard also found that he could not conform to the new pressures arising from demands of performativity. In faculty meetings there is regular reference to his lack of publications (see page 332 of the novel) and students quickly realise that taking Howard's class was not in their best interests because he is,

Underpublished, politically marginal and badly situated. (p.142)

In the private sphere, the changing reality of Howard's deception about his affair emerges at a party being held at the Belsey household. It is revealed that his affair was not a 'once only encounter' at a conference as he earlier admitted. It was a lengthy affair with a work colleague. This compounds the shame of the affair and signals the end of his marriage.

You're married to someone for thirty years: you know their face like you know your own name. It was so quick yet so absolute - the deception was over. (page 120)

These excerpts show that academic identity work is sometimes a precarious activity. It does have a performance element but is also deeply connected to one's most private thoughts and feelings. We can see that for Howard, identity work is a central concern and there are threats to which he must respond and in the end it is difficult to separate the work elements of his identity from the non-work elements. At work, the organisation plan to appoint Sir Monty Kipps to the faculty, the demands to publish and changing cultures (You're talking ... like a management manual?) take their toll on Howard. It seems that his academic identity work is something that affects, and is affected by, external influences and he is unable to adapt to change (beyond ... learning new tricks), and cannot meet professional demands (underpublished and marginal). 


\section{Setting the future}

In the final set of excerpts, we see how the past, present and future collide in identity work. It is here that a convergence of external (institutional and organisational), and internal (individual) influences occur. At the institutional level the influence of family and gender get beyond Howard's personal ability to cope, contributing to the disintegration of his academic identity. At the organisational level, it seems that Wellington University will no longer support his continued employment and at the individual level, he realises that his academic identity is in a state of change.

Ten years in one place without tenure, was a long time ... It was in a university that he must now put all his remaining hope ... He only needed one more: the final, generous institution to take him in his dotage and protect him. (page 437-438)

In the following excerpt, near the end of the novel, Howard is preparing to give a public lecture that would perhaps give him an opportunity of tenure at another University (it's time for tenure). A colleague's email reads:

'This is the big one', read Smith's e-mail of this morning. 'Howard, it's time for tenure. If Wellington can't give you that, you move on. This is how it's supposed to be'. (page 437)

Howard arrives late to the seminar and forgets his notes. Halfway through his preliminary presentation he stops speaking. He sees Kiki (his now estranged wife) in the audience. Howard presents slides of Rembrandt's paintings in silence. This event marks the beginning of a process of identity reconstruction for Howard, perhaps to that of a 'retired academic'. 
In Wellington terms, he was already a dead man walking, with no book coming any time soon, surely heading for a messy divorce and on sabbatical that looked suspiciously like the first step to retirement. (Page 441)

These extracts demonstrate the chronotopic nature of identity work in that they highlight the centrality of time and place (Ten years in one place). At each time and location there are various identity processes at work that cause Howard Belsey, to constantly try to internally reconcile and maintain his identity in the face of shifting external influences. From reading the novel we can conclude that threats to academic identity come from multiple sources and there is a process of constant modification within which there is a constant interplay of various internal and external influences occurring within timespace contexts (Figure 2).

Insert Figure 2 about here

\section{Academic identity work in a runaway world}

Our study of academic identity work suggests that in some ways the situation is one of hopelessness in which there is a constant struggle to keep up in a runaway world. The analysis also reveals academic identity work as an interplay of internal and external influences arising from various available academic identities. This interplay takes place within timespace (chronotopic) contexts that create the conditions for identity work. We illuminate this process and the challenges academics face in maintaining a coherent sense of self (Winkler 2013). The analysis also sheds light on various tensions between organisational, peer, and individual cultural, values, norms, and beliefs that play out in sometimes very 
intimate ways that are difficult to identify and analyse (Fitzmaurice 2013). As detailed in the novel, these conditions often negatively affect motivation, self-efficacy, commitment, job satisfaction and effectiveness (Winter 2009), creating circumstances in which fragilities of an individual's identity (Knights and Clarke 2014) can be exposed and amplified to the extent that their standing as an academic is compromised.

While much of the research about academic identity work suggests that forces beyond the control of academics are sweeping through higher education causing disruption and dislocation, our analysis (Table 2) provides a more complex picture. We can see that there is a range of self and academic identities available and individuals have scope to interpret and modify externally imposed identities arising from institutions. The important thing here is that the extent to which academics embrace particular identities is more than just a function of 'what universities want' at a particular time. Identity-making resources vary from person to person. As detailed in On Beauty, for someone working as an academic, becoming an academic is central to their identity. This endeavour is influenced by personal interactions with and expectations of significant others as well. Our analysis of academic identity work not only reveals the influences of some dimensions of the broad changes to organisational cultures and institutional demands, it also reminds us that we should not underestimate the complex relationships between the personal and the professional in identity work and that class, gender, race, and longstanding characteristics of academe and its institutions as sources of tensions and struggles (e.g., intense peer competitiveness, rivalry, and conflict) are still very much apparent. Of additional importance is that, by applying literary theory, we show that these are embedded within particular timespace (chronotopic) contexts. This matters because people and places are products of their social, economic and political pasts and their expectations for the future. For academic identity work this means that organisations cannot 
control the narrative of a person's past nor can they completely control how a person responds to their work environment and the self-narratives they create. In sum, we can see academic identity work as a narrative process that is a mix of internal processes of self-reflection and action going with and against the grain of external influences taking place within timespace (chronotopic) contextual frames.

\section{Implications and future work}

While this study highlights the potential contribution analysis of narrative fiction can make to research into academic identity work, there are limitations associated with using this type of data that must be accounted for. Firstly, we cannot claim that our reading of the novel is the only correct or the best one; it was though produced through careful and systematic reading and analysis (see also Patient et al. 2005). Secondly, we have used only selected passages from the novel in our analysis. More would have helped, but we were limited by manuscript length. A further limitation is the setting of a small university on the East Coast of the USA. In light of these limitations, we do not make any substantial claims of generalisability. We do though argue that our study has significant implications for theory and research in academic identity work.

Our study is not the first example of research that uses fictional narratives to examine academia, it does though contribute to the literature in that it explores new and interesting theoretical and empirical aspects of academic identity work. For those interested in developing theory that can be generalised more broadly, our study can be used as a starting point for extended research that combines insights from other academic novels with those gained from researching academic identities through more conventional means. Using fictional narratives provides a way of exploring the more intimate details of academic identity work that might not be easily elicited through interviews or observation. It is useful to use 
data collected from interviews and observation to provide clues about interpreting the intimate accounts provided by novels (Alvesson et al. 2008). We also provide new theoretical insights through the use of chronotopes to conceptualise timespace as an important element in academic identity work. In doing so, we provide a sound conceptual base for further theorisation of academic identity work as a narrative process that occurs within various timespace contexts. Finally, we have been able to present academic identity work as a multilevel process.

Our analysis of academic identity work as portrayed in On Beauty has illuminated new dimensions of the process. While controversial, few have disputed the world portrayed and characters that inhabit the novel. Zadie Smith excels at telling the story of Howard Belsey's academic identity work. In many ways, the narrative in On Beauty highlights the constant interaction of forces that are disrupting identity with those that promote coherence and stability. We find that although there may be aspects of academic identity work lost in individual works of narrative fiction, if we use a variety of fictional works we can find out a great deal because, like Zadie Smith, other authors are skilled in the portrayal of human experience. If we choose carefully, our understanding of academic identity work can benefit significantly from their detailed analysis. Our study reveals that defining the process of becoming an academic is to some extent outside our control, but to maintain a coherent sense of who we are in an environment that creates fragmentation, academics need to see that their identities are still ultimately in their own hands. 


\section{References}

Alexiadou, N., and S. van de Bunt-Kokhuis. 2013. Policy space and the governance of education: Transnational influences on institutions and identities in the Netherlands and the UK. Comparative Education 49, no 3: 344-360.

Alvesson, M., K.L. Ashcraft, and R. Thomas. 2008. Identity matters: Reflections on the construction of identity scholarship in organization studies. Organization 15, no. 1: 528.

Alvesson, M., and J. Sandberg. 2011. Generating research questions through problematization. Academy of Management Review 36, no. 2: 247-271.

Alvesson, M., and H. Willmott. 2002. Identity regulation as organizational control: Producing the appropriate individual. Journal of Management Studies 39, no. 5: 619-644.

Archer, L. 2008. Younger academics' constructions of 'authenticity', 'success' and professional identity. Studies in Higher Education 33, no. 4: 385-403.

Ashforth, B.E., H.H. Spencer, and K.G. Corley. 2008. Identification in organizations: An examination of four fundamental questions. Journal of Management 34, no. 3: 325374.

Bakhtin, M.M. 1981. The dialogic imagination: Four essays. Austin: University of Texas Press.

Barnard, R. 2006. Apartheid and beyond: South African writers and the politics of place. Oxford: Oxford University Press.

Barnett, R. 2000. Realizing the university in an age of supercomplexity. Buckingham: SRHE and Open University Press.

Barnett, R., and R. Di Napoli (Eds) 2008. Changing identities in higher education: Voicing perspectives. London: Routledge.

Bauman, Z. 2000. Liquid modernity. Cambridge: Polity Press 
Billot, J. 2010. The imagined and the real: Identifying the tensions for academic identity. Higher Education Research and Development 29, no. 6: 709-721.

Boje, D.M. 2001. Narrative methods for organizational and communication research: Sage series in management research. London: Sage.

Boje, D.M. 2008. Storytelling organizations. London: Sage.

Boland Jr, R.J. 1994. Identity, economy and morality in 'The Rise of Silas Lapham'. In Good novels, better management: Reading organizational realities, edited by Barbara Czarniawska-Joerges and Pierre G. de Monthoux, 115-137. Chur, Switzerland: Harwood.

Brown, A.D., and M. Humphreys. 2006. Organizational identity and place: A discursive exploration of hegemony and resistance. Journal of Management Studies 43, no. 2: 231-257.

Churchman, D., and S. King. 2009. Academic practice in transition: Hidden stories of academic identities. Teaching in Higher Education 14, no. 5: 507-516.

Clarke, C., D. Knights, and C. Jarvis. 2012. A labour of love? Academics in business schools. Scandinavian Journal of Management 28, no. 1: 5-15.

Clegg, S. 2008. Academic identities under threat? British Educational Research Journal 34, no. 3: 329-345.

De Cock, C., and C. Land. 2006. Organization/literature: Exploring the seam. Organization Studies 27, no. 4: 517-535.

Delanty, G. 2008. Academic identities and institutional change. In Changing identities in higher education: Voicing perspectives, edited by Ron Barnett and Roberto Di Napoli 124-133. London: Routledge.

Empson, L. 2013. My affair with the 'other': Identity journeys across the research-practice divide. Journal of Management Inquiry 22, no. 2: 229-248. 
Eugenides, J. 2011. The marriage plot. London: Fourth Estate.

Fanghanel, J. 2012. Being an academic. Abingdon: Routledge.

Fitzmaurice, M. 2013. Constructing professional identity as a new academic: A moral endeavour. Studies in Higher Education 38, no. 4: 613-622.

Giddens, A. 2002. Runaway world: How globalisation is reshaping our lives. London: Profile Books.

Gioia, D.A., and S. Patvardhan. 2012. Identity as process and flow. In Constructing Identity in and around Organizations, edited by Majken Schultz, Stephen Maguire, Ann Langley and Haridimos Tsoukas, 50-62. Oxford: Oxford University Press.

Gordon, G. and C. Whitchurch, 2010. Academic and professional identities in higher education: The challenges of a diversifying workforce. New York: Routledge.

Guzmán-Valenzuela, C., and R. Barnett. 2013. Academic fragilities in a marketised age: The case of Chile. British Journal of Educational Studies 61, no. 2: 203-220.

Harris, S. 2005. Rethinking academic identities in neo-liberal times. Teaching in Higher Education 10, no. 4: 421-433.

Henkel, M. 2005. Academic identity and autonomy in a changing policy environment. Higher Education 49, no. 1-2: 155-176.

Ibarra, H., and R. Barbulescu. 2010. Identity as narrative: Prevalence, effectiveness, and consequences of narrative identity work in macro work role transitions. Academy of Management Review 35, no. 1: 135-154.

Johnson, L. 1995. The life of the mind: American academia reflected through contemporary fiction. Reference Services Review 23, no. 3: 23-44.

King, V. 2013. Self-portrait with mortar board: A study of academic identity using the map, the novel and the grid. Higher Education Research and Development 32, no. 1: 96108. 
Knights, D., and C. Clarke. 2014. It's a bitterswett symphony, this life: Fragile academic selves and insecure identities at work. Organization Studies 35, no. 3: 335-357.

Knights, D., and H. Willmott. 1999. Management lives: Power and identity in work organisations. London: Sage.

Koerner, M.M. 2014. Courage as identity work: Accounts of workplace courage. Academy of Management Journal 57, no. 1: 63-93.

Learmonth, M., and M. Humphreys. 2012. Autoethnography and academic identity: Glimpsing business school doppelgangers. Organization 19, no. 1:99-117.

Leibowitz, B., C. Ndebele, and C. Winberg. 2013. 'It's an amazing learning curve to be part of the project': Exploring academic identity in collaborative research. Studies in Higher Education 39, no. 7: 1256-1269.

Lerum, K. 2001. Subjects of desire: Academic armor, intimate ethnography, and the production of critical knowledge. Qualitative Inquiry 7, no. 4: 466-483.

Lorino, P., and B. Tricard. 2012. The Bakhtian theory of chronotopes (time-space frame) applied to the organizing process. In Constructing identity in and around organizations, edited by Majken Schultz, Stephen Maguire, Ann Langley and Haridimos Tsoukas, 201-234. Oxford: Oxford University Press.

Menard-Warwick, J. 2011. A methodological reflection on the process of narrative analysis: Alienation and identity in the life histories of English language teachers, TESOL Quarterly 45, no. 3: 564-574.

Nikunen, M. 2012. Changing university work, freedom, flexibility and family. Studies in Higher Education 37, no. 6: 713-729.

Nixon, J. 1996. Professional identity and the restructuring of higher education. Studies in Higher Education 21, no. 1: 5-16. 
Patient, D., T.B. Lawrence, and S. Maitlis. 2003. Understanding workplace envy through narrative fiction. Organization Studies 24, no. 7: 1015-1044.

Phillips, N., and S. Zyglidopoulos. 1999. Learning from Foundation: Asimov's psychohistory and the limits of organization theory. Organization 6, no. 4: 591-608.

Raggatt, P.T. 2014. The dialogical self as a time--space matrix: Personal chronotopes and ambiguous signifiers. New Ideas in Psychology 32: 107-114.

Riessman, C.K. 2008. Narrative methods for the human sciences. Thousand Oaks: Sage Publications.

Rhoades, G. 2007. The study of the academic profession. In Sociology of education: Contributions and their contexts, edited by Patricia J. Gumport, 113-146. Baltimore: Johns Hopkins University Press.

Rhodes, C., and A.D. Brown. 2005. Narrative, organizations and research. International Journal of Management Reviews 7, no. 3: 167-188.

Schultz, M., S. Maguire, A. Langley, and H. Tsoukas. 2012. Constructing identity in and around organizations. In Constructing identity in and around organizations, edited by Majken Schultz, Stephen Maguire, Ann Langley and Haridimos Tsoukas, 1-20. Oxford: Oxford University Press.

Sheridan, V. 2013. A risky mingling: Academic identity in relation to stories of the personal and professional self. Reflective Practice 14, no. 4: 568-579.

Skelton, A. 2012. Teacher identities in a research-led institution: In the ascendancy or on the retreat? British Educational Research Journal 38, no. 1: 23-39.

Smith, J. 2010. Forging identities: The experiences of probationary lecturers in the UK. Studies in Higher Education 35, no. 5: 577-591.

Smith, K. 2012. Fools, facilitators and flexians: Academic identities in marketised environments. Higher Education Quarterly 66, no. 2: 155-173. 
Smith, Z. 2005. On beauty. New York: Penguin.

Smith, Z. 2006. On the beginning. Available online at:

http://www.theguardian.com/books/2006/jul/15/zadiesmith (accessed 21 October 2014).

Thelin, J.R., and B.K. Townsend. 1988. Fiction to fact: College novels and the study of higher education. Higher education: Handbook of theory and research 4: 183-211.

Tierney, W.G. 2002. Interpreting academic identities: Reality and fiction on campus. The Journal of Higher Education 73, no. 1: 161-172.

Tierney, W.G. 2004. Academic freedom and tenure: Between fiction and reality. The Journal of Higher Education 75, no. 2: 161-177.

Watson, T.J. 2008. Managing identity: Identity work, personal predicaments and structural circumstances. Organization 15, no. 1: 121-143.

Whitchurch, C. 2008. Shifting identities and blurring boundaries: The emergence of 'third space' professionals in UK higher education. Higher Education Quarterly 62, no. 4: 377-396.

Whitchurch, C. 2009. The rise of the blended professional in higher education: A comparison between the United Kingdom, Australia and the United States. Higher Education 58, no. 3: 407-418.

Whitchurch, C. 2012. Expanding the parameters of academia. Higher Education 64, no. 1: 99117.

Williams, J.J. 2012. The rise of the academic novel. American Literary History 24, no. 3: 561589.

Winkler, I. 2013. Moments of identity formation and reformation: A day in the working life of an academic. Journal of Organizational Ethnography 2, no. 2: 191-209. 
Winter, R. 2009. Academic manager or managed academic? Academic identity schisms in higher education. Journal of Higher Education Policy and Management 31, no. 2: 121-131.

Winter, R.P., and W. O'Donohue. 2012. Academic identity tensions in the public university: Which values really matter? Journal of Higher Education Policy and Management 34, no. 6: 565-573.

Yin, R.K. 2009. Case study research: Design and methods. $4^{\text {th }}$ Ed. London: Sage.

Ylijoki, O.H, and J. Ursin. 2013. The construction of academic identities in the changes of Finnish higher education. Studies in Higher Education 38, no. 8: 1135-1149. 
Table 1. Chronotopes and academic identity work as revealed in On Beauty

\begin{tabular}{|c|c|c|}
\hline Chronotopes & $\begin{array}{c}\text { Available academic identities } \\
\text { (external influences) }\end{array}$ & $\begin{array}{l}\text { Available self-identities } \\
\text { (internal influences) }\end{array}$ \\
\hline Childhood & $\begin{array}{l}\text { Class: } \\
\text { Status of academic work } \\
\text { Race/Culture: } \\
\text { Expectations of different groups }\end{array}$ & $\begin{array}{l}\text { Memory: } \\
\text { Childhood memories } \\
\text { Shame: } \\
\text { Howard Belsey's 'escape' } \\
\text { from his working class } \\
\text { background } \\
\text { Grief: } \\
\text { Howard's insurmountable } \\
\text { sense of loss }\end{array}$ \\
\hline Career struggle & $\begin{array}{l}\text { Social/professional/family/gender: } \\
\text { Norms and expectations of how an } \\
\text { 'academic' should behave } \\
\text { Professional/university/organisational } \\
\text { culture: } \\
\text { Competition between academics for } \\
\text { status as experts in their field and } \\
\text { standards expected of academic as } \\
\text { 'experts' in their field }\end{array}$ & $\begin{array}{l}\text { Shame: } \\
\text { Howard Belsey has his affair } \\
\text { discovered and needs to } \\
\text { protect his reputation which } \\
\text { motivated him to lie } \\
\text { Desire: } \\
\text { Howard Belsey's desire to } \\
\text { become a well-known and } \\
\text { respected academic. } \\
\text { Howard Belsey's initiation } \\
\text { of an affair with a colleague. } \\
\text { Motivation: } \\
\text { Howard Belsey believed he } \\
\text { was right to point out an } \\
\text { error made by another } \\
\text { academic } \\
\text { Humiliation: } \\
\text { Howard Belsey's error } \\
\text { resulted in professional } \\
\text { embarrassment and loss of } \\
\text { reputation }\end{array}$ \\
\hline Changing realities & $\begin{array}{l}\text { Social/professional: } \\
\text { Expectations of what an academic } \\
\text { should be } \\
\text { Organisational culture/organisational } \\
\text { plans and policies: } \\
\text { Requirements of academics } \\
\text { Organisational change }\end{array}$ & $\begin{array}{l}\text { Shame: } \\
\text { Howard's shame about his } \\
\text { affair is compounded when } \\
\text { his lie is discovered } \\
\text { Betrayal: } \\
\text { Howard Belsey feels } \\
\text { betrayed by his colleagues } \\
\text { and university }\end{array}$ \\
\hline Setting the future & $\begin{array}{l}\text { Organisational plans and policies: } \\
\text { Tenured versus non-tenured } \\
\text { academic }\end{array}$ & $\begin{array}{l}\text { Alienation/separation: } \\
\text { From past identity }\end{array}$ \\
\hline
\end{tabular}


Figure 1. The relationship between chronotopes and academic identity work (based on Watson 2008)

Figure 2. Academic identity work process as revealed in On Beauty 


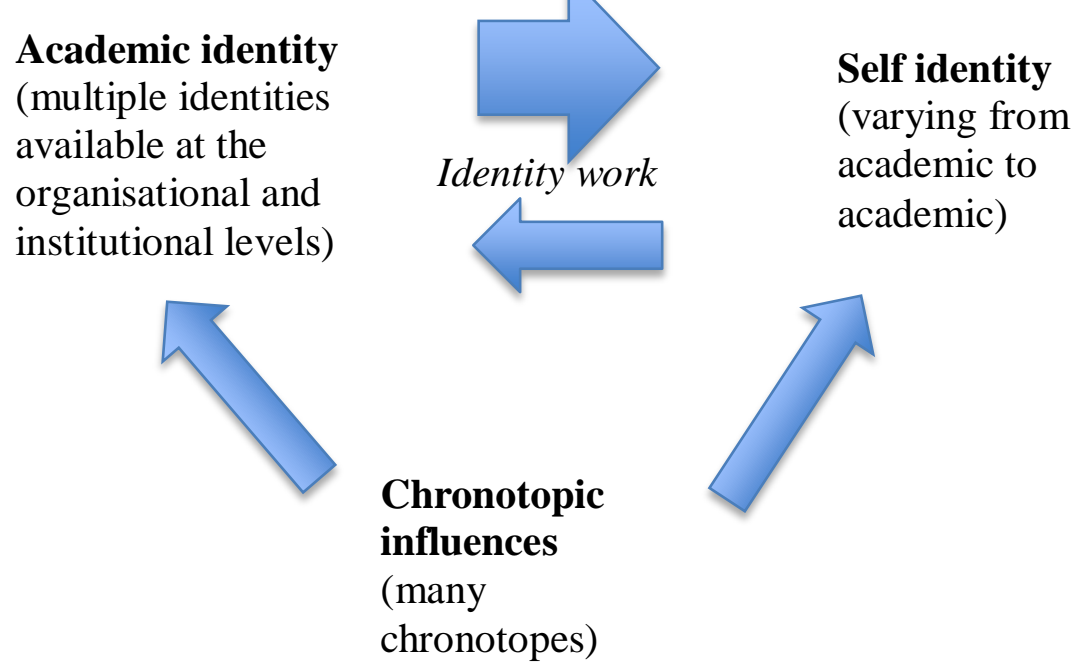

Figure 1. The relationship between chronotopes and academic identity work (based on Watson, 2008) 


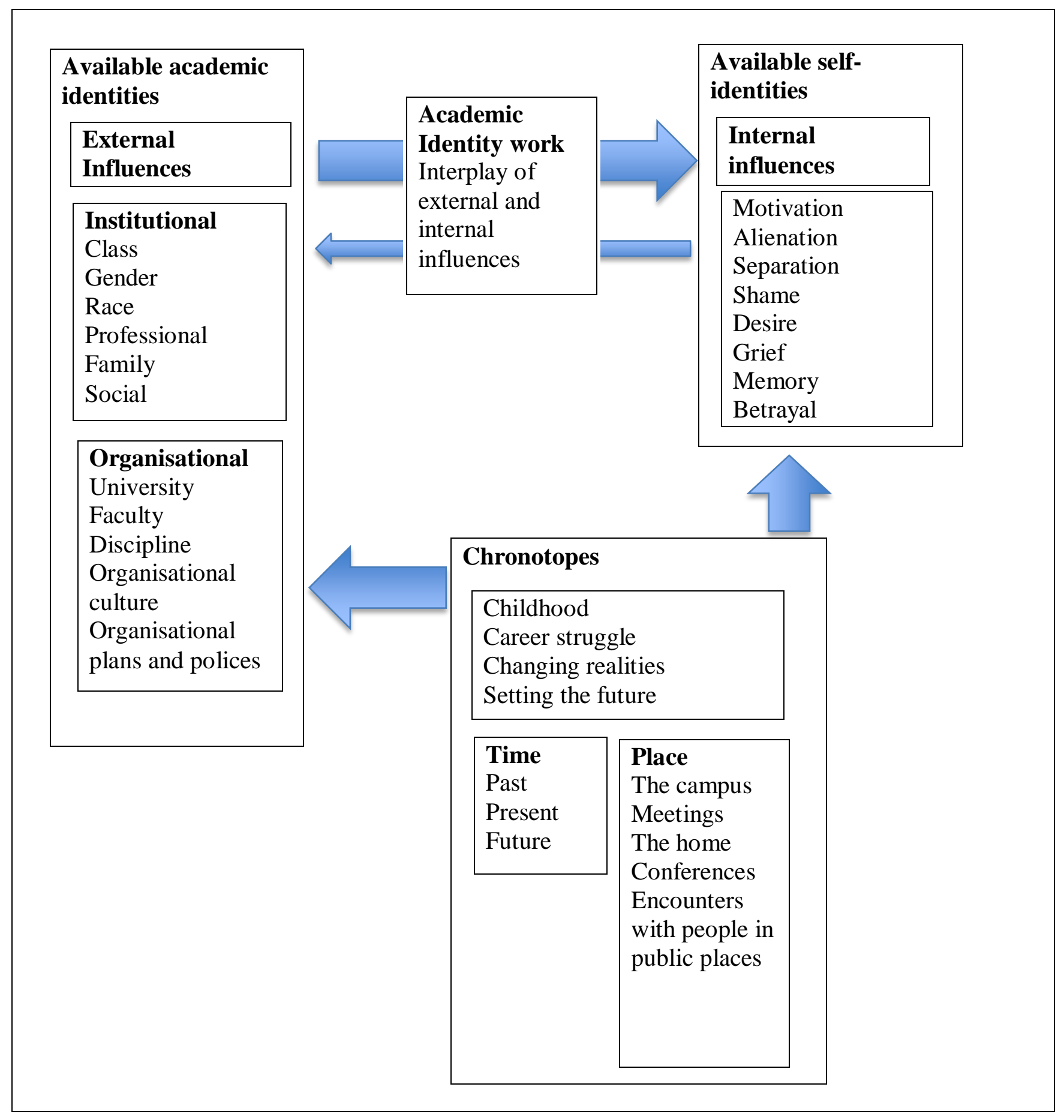

Figure 2. Academic identity work process as revealed in On Beauty 